THEORIA ET HISTORIA SCIENTIARUM, VOL. VI, N 2

Ed. Nicolas Copernicus University 2002

Peter Erdi, Ichiro Tsuda

\title{
Hermeneutic Approach to the Brain: Process versus Device?
}

\begin{abstract}
Hermeneutics, the art of the interpretation, is applied to brain. The relevance of : ?ncepts of hermeneutic processes and hermeneutic devices to brain theory are explained.

\section{Subjective introductory remarks}

This paper is the emergent result of a series of long conversations between the Eithors. They met first in 1983 on a train towards Schloss Elmau, where the : nergetics of the Brain conference was organized by Hermann Haken (Basar et K 1983). The authors believe that dialogs are important to try integrate different ews into a coherent view. The paper is a first attempt to integrate different jspects of the hermeneutic approach to the brain. The paper starts with two

subjective introductions.
\end{abstract}

\subsection{IT: Why did I think on hermeneutic brain?}

In 1982 March and April at Kyoto, in order to write an introductory remark for a PhD thesis entitled "Chaos and Bifurcation Structure in Nonlinear and Nonequilibrium Systems" under the supervision of late Kazuhisa Tomita, I concentrated on knowing the significance of chaos. Among many characteristics of chaos, I payed attention to the role of its uncountability or undecidability within our finite universe. On the other hand, I took a standpoint of accepting a continuum as an entity supporting the appearance of chaos behind. Stimulated 
by Chung-tse's poem on chaos (B.C. 5), I considered that chaos does not manifest itself as it is in a finite universe, and it would change its figure if one tries to articulate it, or in the worst case it will die as Chung-tse pointed out. This way of thinking led me a viewpoint of relativity of observer and object, which gave rise to the studies of effects of noise, finite precision, and partition of observations.

Since these problems also seem to be closely related with epistemology, I started to think of some of hard problems in chaos related to the framework of brain and mind problem. Then, I decided to do a research of the brain in order to understand the implications of problems such as (1) What allows the existence of chaos? (2) What is allowed by chaos?

At that time, Hiroshi Shimizu was looking for a young researcher for his national project, named „Bioholonics” (the name holonics comes from the concept of „holon” invented by Arthur Koestler). At the beginning of this project, an already-decided issue was a fundamental policy, i.e. to find a new biological- computational principle based on the principle of self-organization, namely to find a relation between a whole and a part from the aspect of ,holon”. Shimizu gave me the freedom to choose my own theme in this project. I proposed brain research, and he promptly accepted. Soon it became a central theme in the project.

I started to study in 1982 October at Tokyo the past results in brain sciences, and was naturally guided to the contributions of David Marr. I read the papers of Marr (Marr, 1969, 1970, 1971), and found them most essential. In particular, I was attracted to his idea what a brain theory should be. Learning his whole contribution, which is nowadays being successfully followed by his colleagues, I noticed a double structure in his brain theory such that a hermeneutic approach is adopted to interpreting neurons. Suppose neurons output an electric signal as a result of which each of them or ensemble interprets a structure of outer world with a help of sensory signals. What a neuron is doing, it is an interpretation. Our purpose is to understand what related to this process. We don't know, however, the basic principle in this phenomenological world, in advance. In other words, we do not know preunderstanding of the transformation rule of physical signal to information and also to meaning. Therefore, our act itself must be interpretative.

Apparently, this double structure is inevitable in the historical and social sciences, and in archaeology. One will see a similar structure of theory also in cosmology and geophysics. Also in brain sciences, such a double structure is inevitable to progress our understanding on the brain and mind. Hermeneutics provides a framework, in which an art of interpretation has developed. Therefore, how to commit the „external” world and then how to participate in the world are investigated in this framework (Heidegger 1927). In this sense, hermeneutics is also a pragmatics, namely a science providing a method how to behave and how to communicate in real time with the rest of the world. Essential problems occuring here are not exophysical but endophysical (Rossler 1987). 
Summarizing a philosophical hermeneutics, and applying a hermeneutic method to the brain sciences, I put a bit forward a hermeneutic theory of brain in 1984 (Tsuda 1984). The characteristics of my hermeneutic theory is that it includes chaos as a gadget assuring a process of interpretation of the brain and maintain above double structure. The brain interprets both the external and internal world, responding to its image created inside. This process requires an internal dynamics which assures both variety and parsimony. In order to satisfy these conditions chaotic dynamics is necessary (Nicolis and Tsuda 1985). This kind of internal dynamics was actually observed in animal motivated learning and perception (Freeman 1991). Thus we construct an interpretative theory, in which we interpret the brain activities in terms of chaotic dynamics, based on the difference between internal logic of observed brain and external logic of observer.

\subsection{PE: Hermeneutics of the brain}

In the Orwellian year Tsuda's paper and the Hungarian translation of Gadamer's book (Gadamer I960, 1976, 1984) was published in Hungarian. I was schocked by Tsuda's paper. Generally, in the community of physicist, perhaps not always openly admittedly, (and even before the Sokal hoax) philosophy and the htrman sciences had a bad reputation. Tsuda took the encouragament to submit a paper using philosophical terms about the brain to a physics journal (and, what is more surprising, the editors accepted it.)

Gadamer's book was offered to me by my friend Peter Balassa, a famous Hungarian aesthete. In the late eighties I edited a Special Issue on Art and the New Biology: Biological Forms and Patterns for the Leonardo, which is the Journal of the International Society for the Arts, Sciences and Technology. In the Editorial I argued to find the connection between biology and aesthetics (Erdi 1989):

„There are many lines connecting the biological sciences to aesthetic principles. The beauty of plants, animals and humans is connected to ratios (e.g. divine proportion), to symmetry and symmetry breaking, to colours. Our ability to perceive psychologically and to accept aesthetically the temporal order of poems and music is based on neurophysiological processes taking place in our brains.

Biological systems contain their own descriptions, therefore they can be considered self-referential systems. While it is rather obvious that, despite the methodological success of the analytical sciences, the marvellous complexity of life cannot be explained completely in terms of physics, it must be admitted that aesthetics, in particular philosophical hermeneutics - emphasizing the necessity of a self-reflexive interpretation offers a fruitful approach to theoretical biology." 
My appeal to hermeneutics has been increased during the rising phase of postmodern ideas. While the celebrated scientific disciplines of the modem age have been adopted the atomist view, such as particle physics and molecular biology, the study of organization principles were considered much less, as „main stream” sciences. I also was impressed by Koestler's holon concept, and more generally was interested in organization principles.

To go further with the scope and limits of the physicalist and the philosophical views I played with the idea (Erdi 1996) how, if at all, the „device approach” and the „philosophical approach” can be reconciled. It was cautiously suggested by turning to the philosophical tradition that hormeneutics, i.e., the ,art of interpretation”, which is neither monist nor dualist a priori, can be applied to the brain. Even a little bit more was stated: on one side the brain is an „object" of interpretation, on the other side, it is itself an interpreter: the brain is a hermeneutic device.

\section{Hermeneutics: a short survey}

Hermeneutics is a branch of continental philosophy which treats the understanding and interpretation of texts. The methodological hermeneutics was established to interpret the texts. The philosophical hermeneutics emphazised the existential understanding instead of interpretation. The crtical hermeneutics offers a methodologically selfreflective reconstruction of the social foundations of discourse and inter-subjective understanding. Finally, the phenomenological hermeneutics is an attempt to synthesize the various hermeneutic currents. For an excellent introduction for non-philosophers, see Mallery et al. 1987.

One of the most important concept of the hermeneutics is the hermeneutic circle. This notion means that definition or understanding of something employs attributes which already presuppose a definition or understanding of that thing. The method is in strong opposition of the classical methods of science, which does not allow such kinds of circular explanations.

\subsection{Classical Methodological Hermeneutics}

Based on Schleiermacher's proposal Dilthey (1923) developed a philosophy of method for the human sciences. He hoped to produce objective knowledge but still avoid the „reductionist, mechanistic, ahistorical” explanatory approach of the natural sciences. One of the most important concept of each type of hermeneutics is the hermeneutic circle. This notion means that definition or understanding of something employs attributes which already presuppose 
a definition or understanding of that thing. The method is in strong opposition of the classical methods of science, which does not allow such kinds of circular causal explanations.

\subsection{Philosophical Hermeneutics}

Heidegger (1927) in Being and Time transfers Dilthey's methodological hermeneutic circle is to a more fundamental ontological hermeneutic circle, which leads from existential understanding to a self-conscious interpretation.

Gadamer ( 1976), Heidegger's student writes: „Understanding always implies a preunderstanding which is in turn prefigured by the determinate tradition in which the interpreter lives and that shapes his prejudices."

\subsection{Critical Hermeneutics}

Critical hermeneutics states that inter subjective communication is possible, despite differences in the participants' pre-understandings. The Habermas (1981) - Gadamer debate helped to clarify the necessity of self-reflection to analyze psychotherapical or social (well, we may say „complex”) systems.

\subsection{Phenomenological Hermeneutics}

Ricoeur strives for a grand synthesis in his phenomenological hermeneutics. As Mallery et al (1986) states: „Ricoeur (1973) attempts a dialectical resolution of the Habermas-Gadamer debate, arguing that, the hermeneutics of tradition and the critique of ideology require each other...”. Also they point out that ,...Ricoeur's hermeneutic arc combines two distinct hermeneutics: one that moves from existential understanding to explanation and another that moves from explanation to existential understanding..."

\subsection{Hermeneutics and science}

The eventual role of the hermeneutics in (natural) sciences has been, and still is, very controversial. To his contribution to the Sokal hoax Weinberg (1996) wrote: ,....(A physicist friend of mine once said that in facing death, he drew some consolation from the reflection that he would never again have to look up the word ,hermeneutic” in the dictionary.)..." 
In the last decade the traditional view, i.e. that hermeneutics is nothing to do with science, has been challenged (see e.g. Feher et al. 1999). At the surface level, scientific activities and scientific texts can be analyzed by hermeneutics tools. More deeply, it is associated to the objectivity-subjectivity dilemma.

Robert Rosen (1993) recalled the physicist's approach, which denies that mind can be the object (or subject) of legitimate scientific study, since it cannot be identified with objective reality. Rosen's analysis points out that this kind of objectivity is narrowly understood and based on mechanistic notions. He also remarks that biologists adopt a more narrow concept of objectivity: it should be independent not only from perceptive agents, but also from the environment: to explain wholes from parts, that is „objective”, but parts in terms of wholes, that is not. To put it another way: closed causal loops are forbidden in the „objective" world. Rosen's conclusion is that the world of systems determined by linear (and only linear) causal relationships belongs to the class of ,simple systems” or mechanisms. The alternative is not a ,subjective” world, immune to science, but a world of complex systems, i.e., one which contains closed causal loops.

Systems with feedback connections and the systems of these connected loops can be understood based on the concepts of circular and network causality (Sattler 1986). Leaving the clear and well-organized world of linear causal systems we find ourselves in the jungle of the second order cybernetics (e.g., Maruyama 1963, Von Foerster 1976, Glanville 1987), and of autopoiesis (Maturana and Varela 1980), which gave a fresh look on the „objectivity-subjectivity” dilemma.

\subsection{The hermeneutics of life}

Kampis (1999) considers hermeneutics ,as a particular way of acting as related to the acqusition, processing, and generation of information." His thinking on the hermeneutics of life adopts a non-structuralist approach. Hermeneutic phenomena can be found at several levels of biological organization, from molecular, via cellular to organism and population levels. While at lower levels molecular recognition, autoimmune diseases can be mentioned as examples where cells to themselves, Kampis emphasizes evolution theory. There is a two- directional process: the results of previous selections can become selective forces for new development.

\section{Hermeneutic process of the brain}

In a series of papers (Tsuda 1984, 1991, 1992, 1993, 1997, Nicolis and Tsuda 1985, Matsumoto and Tsuda 1987, Tsucla et al. 1987, Tsuda and Tadaki 
1997, Tsuda and Yamaguchi 1998) Tsuda developed the framework of a theory of brain and mind based on chaos theory.

In low-dimensional dynamical systems, four classes of attractors are known, that is, the fixed point, the limit cycle, the tori, and the strange attractor. Each attractor may represent a steady state, a periodic state, a qusi-periodic state, and a chaotic state, respectively. Chaos can be characterized by the presence of positive Lyapunov exponent, that is, the orbital instability defined by the exponential separation of nearby orbits in average. In this sense, chaos can exist also in highdimensional dynamical systems. One example is hyperchaos (Rossler 1983) which is characterized by more than one positive Lyapunov exponents. Chaotic transition shown below, however, leads us to another type of chaotic behavior.

\subsection{Chaotic itinerancy}

Specifically, Tsuda in unanimous cooperation with Ikeda and Kaneko (Ikeda et al 1989; Kaneko 1990) proposed the notion of chaotic itinerancy as a universal dynamical concept in high-dimensional dynamical systems. The starting point is a dynamical system which can be characterized by the coexistence of attractors. A state can be a particular attractor. This attractor, however, may become unstable, while other attractors could preserve their stability, i.e. the instability can remain localized. The trajectory of the dynamical system moves along the unstable manifold, and approaches another attractor. If instability is strong enough, many chaotic modes appear and consequently the system goes toward a turbulent state, that is, a quite noisy macroscopic state. Then, even a „trace” of original attractors dissapears. If instability is, however, not so strong, an intermediate state between order and disorder can appear. The dynamics may be regarded as an itinerant process which insures a transition among states which were at the beginning described as an attractor but now are no longer an attractor. In this case, a crucial characteristic is that a „trace" of attractor remains in spite of the generation of unstable directions in the neighborhood of attractors.

\subsection{Nowhere-differentiable attractors}

Certain dynamical systems have a specific property, namely they have singularcontinuous nowhere-differentiable attractors. A singular continuity is generally defined on Cantor set (Rossler et al 1992; Tsuda and Yamaguchi 1998). Tsuda showed that even specific neurodynamic models may lead to nowhere- differentiable attractors. The simple model he studied (Tsuda 1996) belongs to the class of chaos-driven contraction mapping. 
There are two kinds of information processings on the Cantor sets. One is the localization of information on the Cantor set, and the other is the concurrent process of write-in („learning”) and read-out (,retrieval”). The information distributes over subsets of the Cantor set. In other words, an itinerary of time series created by chaotic dynamics is embedded into a geometrical hierarchy of Cantor set. This structure insures a categorization of stochastic time series. Furthermore, this characteristic can be found in various areas of the brain, because a similar anatomical structure to unidirectional couplings of unstable network to stable network is present in, for example, the hippocampus and the olfactory system.

\subsection{Information processing and cognition}

His analyis on information precessing and cognition led a set of propositions (Tsuda, 2001).

1. Information is dynamically preserved in chaotic behaviors of the network of nonuniform chaos.

2. The learning capability of neural networks increases in the presence of chaotic itinerancy.

3. Because of chaotic itinerancy, neural networks can judge whether or not inputs are close to memories.

4. Because of chaotic itinerancy, neural networks can perform an effective search of memory.

5. Because of chaotic itinerancy, neural networks can simultaneously perform learning and recall.

6. Memory can be represented not by a state, but by a process.

7. Memory and information processings cannot be distinguished.

\subsection{Neural hermeneutics}

One of the most essential notions for higher functions of the brain is probably „preunderstanding”. Brain interprets meanings of external stimuli, based on the sensory information. The purpose of the brain in this context is to understand the world. According to Heidegger, however, an interpretation is based on understanding, but not vice versa. An interpretation is prescribed as the process of understanding itself becoming well-formed. Hence, some structure must be assumed in this process, which is named a preunderstanding. Here, the completeness of meaning is assumed in such a way that only the things possessing a completely unified meaning can be understood. With a basis of preunderstanding, a circle between the process of understanding and that of interpretation emerges, which 
can be identified with the hermeneutic circle. With a basis of preunderstanding, a circle between the process of understanding and that of interpretation emerges, which can be identified with the hermeneutic circle.

A preunderstanding for meaning of the sensory information in the cortex is seemingly given by the higher level in the form of values and logics which manifest itself through actions or behaviors. The basic logic here can be viewed as a kind of preunderstanding.

A self-reflective thing may be represented by multi-feedback loops of neural networks. In order to express the relation between the dynamics at higher functional level and the one at lower functional level, functional equations may be necessary. Then, functional equations formulate a self-description of mental process. We do not usually find invariance in functional space, rather find a variety of solutions due to the chaotic behavior of the arguments of function, where the chaotic behavior represents a lower level's activity. This might express the process of a hermeneutic circle continuing after the convergence of self-description.

\section{The brain as a hermeneutic device}

\subsection{Metaphors}

Metaphors provide concepts and relationships between these concepts to understand the mechanisms of phenomena, and proved to be useful to analyze biological systems (Paton 1992). The brain (The Metaphorical Brain, as it is suggested by Arbib 1989 has been described by different metaphors. First, there are the technical brain analogies: technical devices, as telegraph circuits, holograms and of course computers have been offered as metaphors and/or models of true brain. Second, theoretical notion of phyiscs from quantum physics to thermodynamics served as analogies for characterizing neural functioning of the physical brain. Third, there is the notion of the computational brain (Churchland and Sejnowski 1992). More precisely, the metaphor has two directions („brain as a computer” versus „computer as a brain”). Fourth, the philosophical brain has been approached by a variety of theories, each finally labelled as either monist or dualist, but none of them proved capable of meeting the strict criteria which the neurosciences seem to offer. In an earlier paper (Erdi 1996) we argued that the philosophical tradition of hermeneutics, i.e., the „art of interpretation”, which is a priori neither monist nor dualist, can be applied to the brain. Playing with the idea that the „technical” or ,device approach” to the brain and the philosophical approach can be reconciled, it was concluded that the brain is a physical structure which is controlled and also controls, learns and teaches, process and creates information, recognizes and generates patterns, organizes its 
environment and is organized by it. It is an „object” of interpretation, but also it is itself an interpreter. The brain not only perceives but also creates new reality: it as a hermeneutic device.

\subsection{The device approach}

The brain can be considered as different types of device. In a series of publications the need of a neurodynamic system theory was demonstrated (Erdi 1983, 1988, 1993, 1999, 2000, Arbib et al 1997, Szentagothai and Erdi 1989, and difierent aspects of a device approach was intorduced. (For more details see Erdi (1996).

We analyzed several ramifications:

The brain as a thermodynamic device

The brain as a control device

The brain as a learning device

The brain as a computational device

The brain as an information storing, processing and creating device

The brain as a self-organizing device

The device approach is strongly related to the dynamic metaphor of the brain (Erdi 2000). Dynamic system theory offers a conceptual and mathematical framework to analyze spatiotemporal neural phenomena occurring at different levels of organization, such as oscillatory and chaotic activity both in single neurons and in (often synchronized) neural networks, the self-organizing development and plasticity of ordered neural structures, and learning and memory phenomena associated with synaptic modification.

\subsection{The philosophical brain}

Attempts „to solve" the brain-mind problem can be classified into two basic categories: (1) materialistic monism, leading in its ultimate consequences to some kind of reductionism; (2) interactionist dualism, which is more or less some type of Neo-Cartesian philosophy. The classification is, obviously, a crude oversimplification: a wide spectrum of monistic theories exist from Skinner's (1971 radical behaviourism and Patricia Churchland's (1986) eliminative materialism, through Smart's (1981) physicalism to Bunge's $(1977,1980)$ emergent materialism. Interactionist dualism has always been an influential world concept since Descartes defined the interaction between the spatially extended body and a non-corporeal mind. Though its modem version was elaborated by two intellectual heroes of the twentieth century (Popper and Eccles 1977), still it 
has been criticised even ignored, both by the representatives of the „main stream” of the philosophy of mind, mostly as functionalists, as well as by biology-oriented thinkers.

„Downward causation”, i.e., that mental agents can influence the neural functioning, was suggested by Sperry $(1969,1980)$. Sperry was criticised by stating that the postulate that physiological mechanisms of the brain are directly influenced by conscious processes is unclear (Edelman 1978, Szentagothai and Erdi 1983). Alternatively, it was cautiously suggested, that the nervous system can be considered as being open to various kinds of information, and that there would be no valid scientific reason to deny the existence of downward causation, or more precisely, a two-way causal relationship between brain and mind (Szentagothai 1984).

Neuronal bases of consciousness again became a hot issue (see e.g. Taddei- Ferreti and Musio 1999). Philosophical analysis should be based on specific questions (Hameroff 1999).

- How to characterize the correlation between brain states and mental states?

- Where does conscious vision occur in the brain?

- Is consiousness computation?

- Do single neurons process information relevant to consciousness?

- Is consciousness the emergent product of nonlinear hierarchical brain dynamics?

- Is there any relationship between quantum computing and consciousness?

Whatever the successful experimental approach (leading to „laboratory philosophy"; the terminology courtesy George Kampis) will be a new look at the old problem even from the philosophical point of view may be necessary.

\subsection{The interpreting and the interpreted brain}

It was argued that there seems to be a convergence between the „device approach” and the „philosophical approach” to the brain. Systems exhibiting ,high” structural complexity AND ,high” dynamic complexity” (e.g., but not exclusively, chaos) may be candidates of being hermeneutic devices, since they are both object or subject of interpretaion and interpreting agents. (It should be recalled, however, that even simple systems may lead to complex dynamics (May 1976)). So, the occurrence of chaos is not a sufficient condition for being a hermeneutic device.

Based partially on Freeman's findings and concepts (Freeman 1975, 1991) Tsuda (1984, 1991) suggested that (i) a particular chaotic phenomenon, namely chaotic itinerancy, may be identified with what he calls hermeneutic process; (ii) in opposition to the idea that ,the brain is a computer, the mind is a programmer", 
„...the brain can create even a programmer through the interpretation process expressed by chaotic itinerancy...” (Tsuda 1991).

What we have learned is that the brain is a physical structure which is controlled and also controls, learns and teaches, processes and creates information, recognizes and generates patterns, organizes its environment and is organized by it.

Both natural science as „objective analyzer” and (post)modem art reiterate the old philosophical question: What is reality? The human brain is not only able of perceiving what is called objective reality but also can create new reality. It is a hermeneutic device.

\section{Conclusions}

The authors of this paper agree that the philosophical approach to the brain is an obligation. Even more is true, the brain (and the mind) certainly cannot be considered as a simple mechanism; it is a prototype of complex systems. Kaneko and Tsuda (1994, 2001) speaks about constructive complexity. Internal observation is an important concept in understanding how the brain understands itself. If chaos is really relevant to characterize brain activities in many cases, chaos can be a candidate of such an internal observer. This viewpoint has been called as chaotic hermeneutics by one of us (IT) (Tsuda 1993). The brain constructs new reality: it is a hermeneutic device

\section{Acknowledgments}

This work was supported by the National Scientific Research Foundation (OTKA) T 025500, T 025472. (P. E) and also partially by the Grant-in-Aid no. 10440054 for Scientific Research from the Ministry of Education, Science, Sports, and Culture of Japan. (IT).

\section{References}

Arbib M. A.: 1989, The Metaphorical Brain 2: Neural Networks and Beyond, New York: Wiley-Interscience.

Arbib M., Erdi P., Szentagotai J.: 1997, Neural Organization: Structure, Function and Dynamics. The MIT Press, Cambridge-London.

Basar E., Flohr H., Haken H., Mandell A. J., (eds.) 1983, Synergetics of the Brain. Berlin, Springer-Verlag.

Bunge M., 1977, Emergence and the mind. Neuroscience 2(501-509). 
Bunge M., 1980, The mind-body problem. Pergamon Press.

Churchland P. S., 1986, Neurophilosophy:Toward a Unified Science of the Mind-Brain.

The MIT Press, Cambridge, Mass.

Churchland P. S., and Sejnowski T., 1992, The Computational Brain. A Bradford Book.

The MIT Press. Cambridge, Mass.

Dilthey, W., 1923, Gesammelte Schriften, B.G Teubner, Leipzig and Berlin.

Edelman G. M., 1978, Group selection and phasic reentrant signalling: A theory of higher brain function. In: The mindful brain: Cortical organization and the group-selective theory of higher brain function, Edelman GM. and Mountcastle VB., eds., pp. 55- -100, The MIT Press, Cambridge, Mass.

Erdi, P, 1983, Hierarchical thermodynamic approach to the brain, Int. J. Neurosci. 20(193-216).

Erdi P, 1988, Neurobiological approach to computing devices. BioSystems 21(125-133) Erdi P, 1993, Neurodynamic system theory: scope and limits. Theoret. Medicine 14(137-152).

Erdi P, 1989b, Biology and Art. Editorial to the Special Issue „Art and the new biology:

Biological forms and patterns". Leonardo 22(1-2).

Erdi, P, 1996, The brain as a hermeneutic device. BioSystems 38(179-189).

Erdi P, 1999, Neural and mental development: selectionsim, constructivism, hermeneutics.

Neuronal bases and pscychological aspects of consciousness (ed. Taddei-Ferrati,

C), World Scientific, pp. 507-518.

Erdi P, 2000, On the 'Dynamic Brain' Metaphor, Brain and Mind 1(119-145).

Feher M., Kiss O. and Ropolyi L., (eds.), 1999, Hermeneutics and Science. Boston Studies

in the Philosophy of Science, Vol. 206, Kluwer Acad. Publ. Dordrecht-Boston-London.

Freeman, W. J., 1975, Mass action in the nervous system, New York: Academic Press. Freeman W. J., 1991, The physiology of perception. Sci. Am. 264(78-85).

Gadamer H.-G., 1960, Wahrheit und Methode, Tubingen.

Gadamer H.-G.: Truth and Method. Sheed and Ward: London, 1976. (in Hungarian: 1984). Glanville R., 1987, The question of cybernetics. Cybernetics and Systems 18(99-112). Habermas J., 1981, The Theory of Communicative Action, vol. 1, Reason and the

Rationalization of Society, T. McCarthy, trans, Beacon Press, Boston.

Hameroff S., 1999, Consciousness studies: an overview. In: Neuronal bases and psychological aspects of consciousness, Taddei-Ferretti C. and Musio C., eds., World Scientific, Singapore.

Heidegger 1927, Sein und Zeit, Niemeyer, Tubingen.

Ikeda K., Otsuka K. and Matsumoto K., 1989, Maxwell-Bloch turbulence. Prog. Theor. Phys. Suppl. 99(295-324).

Kampis G., 1999, The hermeneutics of life, In: Feher M., Kiss O. and Ropolyi L., (eds.), Hermeneutics and Science. Boston Studies in the Philosophy of Science, Vol. 206, Kluwer Acad. Publ. Dordrecht-Boston-London, pp. 157-169.

Kaneko K., Tsuda I., 1994, Constructive complexity and artificial reality: an introduction. Physica 75D(1-10).

Kaneko K., Tsuda I., 2001, Complex Systems: chaos and beyond - A constructive approach with applications in life science, Springer-Verlag, Berlin-Heidelberg. 
John C. Mallery, Roger Hurwitz, Gavan Duffy, 1987.

Hermeneutics: From Textual Explication to Computer Understanding? Published in The Encyclopedia of Artificial Intelligence, Stuart. C. Shapiro, editor, John Wiley \& Sons, New York, (see also: http://www.ai.mit.eclu/people/icma/papers/1986-ai-memo871/tableofcontents3_1.html

Marr D., 1969, A theory of cerebellar cortex. J. Physiol. (Lond.), 202(437-470).

Marr D., 1970, A theory of cerebral neocortex. Proc. R. Soc. Lond. B. 176(161-234). Marr

D., 1971, Simple memory: a theory of archicortex. Phil. Trans. R. Soc. Lond. B. 176(161-234).

Maruyama N., 1963, The second order cybernetics: Deviation amplifying mutual causal processes. General Systems 8(233-241).

Matsumoto K., and Tsuda I., 1987, Extended information in one-dimensional maps, Physica $26 \mathrm{D}(347-357)$.

Maturana H. R., Varela F. J., 1980, Autopoiesis and Cognition, Reidel, Dordrecht.

May R. M., 1976, Simple mathematical models with very complicated dynamics. Nature 261(459-467).

Nicolis J. S. and Tsuda I., 1985, Chaotic dynamics of information processing: The 'magic number seven plus-minus two' revisited. Bull. Math. Biol. 47(343-365).

Paton R., 1992, Towards a metaphorical biology. Biology and Philosophy 7(279-294).

Popper K. R. and Eccles J. C., 1977, The self and its brain. Springer Verlag, Berlin. Ricoeur, P., „Hermeneutique et critique des ideologies,” in E. Castelli, ed, Demythisation et ideologie, Aubier Montaignf, Paris, 1973, 25-64.

Rosen R., 1993, Drawing the boundary between subject and object: comments on the mindbrain problem. Theoret. Medicine 14(89-100).

Róssler O. E., 1983, The chaotic hierarchy, Z. Naturforschung 38a(788-801).

Róssler O. E., 1987, Endophysics, In: Casti J., Karlqvist A. eds., Real Brains - Artificial Minds, North-Holland, New York.

Róssler, O. E., Wais R. and Róssler R., Singular-continuous Weierstrass function attractors. In Proc, of the 2nd Int. Conf, on Fuzzy Logic and Neural Networks. Iizuka, Japan (1992) pp. 909-912.

Sattler R., 1986, Biophilosophy. Analytic and holistic perspectives. Springer-Verlag, Berlin Heidelberg-New York-Tokyo.

Skinner B. F., 1971, Beyond Freedom and Dignity. Knopf, New York. Smart JJC, 1981, Physicalism and emergence. Neuroscience 6(109-113).

Sperry R. W, 1969, A modified concept of consiousness. Psychol. Rev. 76(532-536). Sperry

R. W., 1980, Mind-brain interaction: mentalism yes; dualism, no. Neuroscience 5(195-206).

Szentagothai J., 1984, Downward causation? Ann Rev. Neurosci. 7(1-11).

Szentagothai J., Erdi P., 1989, Self-organization in the nervous system. J. Soc. Biol. Struct. 12(367-384).

Taddei-Ferreti C., and Musio C., (eds.), 1999, Neuronal bases and psychological aspects of consciousness. World Scientific, Singapore.

Tsuda I., 1984, A hermeneutic process of the brain. Prog. Theor. Phys. Suppl., 79(241-259).

Tsuda I., 1991, Chaotic itineracy as a dynamical basis of hermeneutics in brain and mind. World Futures, 32(167-184). 
Tsuda I., 1992, Dynamic link of memory - chaotic memory map in monequilibrium neural networks. Neural Networks 5(313-326).

Tsuda I., 1993, Chaotic hermeneutics for understanding the brain. In: endophysics: the world from within. A new approach to the observer-problem with applications in physics, biology and mathematics, Kampis G., and Weibel P., eds. Aerial, Santa Cruz, pp 219234.

Tsuda I., 1996, A new type of sel-organization associated with chaotic dynamics in neural networks. Int. J. Neural Systems 7(451-459).

Tsuda I., 1997: On the complexity of logic-dyanmics in brain. In: Complexity and Diversity, Nakamura, Ed., Springer-Verlag, Tokyo, pp. 37-45.

Tsuda I., 2001, Toward an interpretation of dynamic neutral activity in terms of chaotic system. Behavioral and Brain Sciences 24 (in press).

Tsuda I., Kómer E., Shimizu H., 1987, Memory dynamics in asynchronous neural networks, Prog. Theoret. Phys. 78(51-71).

Tsuda I. and Tadaki K. 1997, A logic-based dynamical theory for a genesis of biological threshold. BioSystems 42(45-61).

Tsuda I. and Yamaguchi A., 1998, Singular-continuous nowhere-differentiable attractors in neural systems. Neural Network 11(927-937).

von Foerster H., 1976, Notes on an epistemology for living things, In: L'Unite de l'Homme, Morin E., ed., Edition de Sevel, Paris.

Weinberg S., 1996, Sokal's Hoax, Steven Weinberg, The New York Review of Books, Volume XLIII, No. 13, pp 11-15, August 8. 